\title{
AVALIAÇÃO DA QUALIDADE DE FRUTOS DE CAFÉ ATACADOS POR Ceratitis capitata (WIEDEMANN, 1824) (DIPTERA: TEPHRITIDAE)
}

\author{
F.J. CIVIDANES \\ Departamento de Entomologia e Nematologia - FCAV/UNESP - CEP: 14870-000 - Jaboticabal,SP \\ O. NAKANO \\ Departamento de Entomologia - ESALQ/USP - C.P. 9, CEP: 13418-900 - Piracicaba, SP. \\ M. MELO \\ Departamento de Química - ESALQUSP - C.P. 9, CEP: 13418-900 - Piracicaba, SP.
}

RESUMO: Foram usadas plantas de Coffea arabica L., variedade Catuá Venmelho, localizadas no Campus da Escola Superior de Agricultura "Luiz de Queiroz" - USP, Piracicaba,SP, para avaliaçāo dos danos que Ceratitis capilata (Wied., 1824) pode causar aos frutos do cafeeiro. Os resultados mostraram que o ataque de $C$. capitata não causou queda prematura dos frutos. mas aumentou a queda de cerejas e foram encontradas, fortes evidências, com base na atividade da enzima polifenol oxidase e lixiviação de potássio, que cerejas atacadas podem produzir bebida de café de qualidade inferior.

Descritores: Ceratitis capilata, mosca-do-mediterrâneo, café, polifenol oxidase, lixiviação de potássio.

\section{EVALUATION OF TIE QUALITY OF COFFEE FRUIT ATTACKED BY Ceratitis capitata (WIEDEMANN, 1824) (DIPTERA: TEPIIRITIDAE)}

\begin{abstract}
The present work was carried out using trees of Coffea arabica L. variety Red Catuaí grown at Escola Superior de Agricultura "Luiz de Queiroz" - Campus of the University of São Paulo, Piracicaba,SP. The objective was to estimate damages that Ceratitis capilata (Wied., 1824) can cause to coffee fruits. The results showed that C.capiata did not cause premature fruit fall, but it increased berry fall. The activity of the enzyme polyphenol oxidase and potassium lixiviation give strong evidences that atacked coffee beans produce coffee beverage of inferior quality.
\end{abstract}

Key Words: Ceratitis capitata, mediterranean fly, coffee, polyphenol oxidase, potassium leching

\section{INTRODUÇÃO}

Dentre as várias espécies de tefritídeos existentes no Brasil, a mosca-do-mediterrâneo Ceratitis capitata (Wied., 1824), destaca-se pela importância para a fruticultura. Ela é encontrada com maior frequência nas regiōes sul e sudeste, onde, geralmente, se cultiva o maior número de frutiferas exóticas, as quais constituem seus principais hospedeiros (MALAVASI et al., 1980).

O cafeeiro é considerado um ótimo hospedeiro da C.capitata, sendo também importante sob o ponto de vista ecológico, pois possibilita à mosca-do-mediterrâneo, persistir nas áreas rurais em que vive (MARICONI \& IBA, 1955; PUZZI et al., 1957). No entanto, sua importância como praga do cafeeiro é contraditória (ABASA, 1973), sendo escassas as informações a este respeito no Brasil.
De qualquer modo, o estudo de pragas que possam causar prejuízos à cultura do café é plenamente justificado pela grande importância que esta cultura tem para o nosso país. Atualmente, mais de 300 mil propriedades tem no café, sua principal fonte de renda, explorando as terras, fixando mão-de-obra, criando riquezas e bem estar social. Além disso, estima-se que cerca de 2-3 milhões de pessoas estejam em nosso país, diretamente ligadas à cafeicultura (INSTITUTO BRASILEIRO DO CAFÉ, 1986).

Portanto, existe a necessidade de se obter informações que venham contribuir para o esclarecimento da interação C.capitata e cafeeiro. O presente trabalho teve como objetivo avaliar os possíveis danos que essa mosca pode causar aos frutos e à qualidade da bebida do café.

A mosca-do-mediterrâneo C.capitata é originária da África e sua introdução no Continente 
Americano ocorreu pelo Brasil em 1901 (NUNEZBUENO, 1987). Atualmente, ela se encontra bastante distribuída pelo referido continente, infestando hospedeiros nativos ou exóticos (MATIOLI, 1985). No Brasil, é praga na fruticultura, atacando pêssego, citros, maçã, manga, entre outras, podendo causar perdas de produção de frutíferas comerciais (MALAVASI et al., 1980).

O cafeeiro tem sido indicado como o principal hospedeiro da mosca-do-mediterrâneo (CUCULIZA \& TORRES, 1975; DAXL, 1978), onde as fêmeas ovipositam na cereja de 2 a 5 ovos, cujas larvas se desenvolvem na polpa da mesma, saindo, posteriormente, para pupar no solo (GALLO et al., 1988).

Existem também muitas evidências que colocam C.capitata como a espécie dominante de moscas-das-frutas nos cafezais brasileiros (SOUZA et al., 1975; MALAVASI, 1977). Na referida cultura, PARRA et al. (1982), encontraram uma predominância de população de $C$.capitata nos meses de maio a setembro, coincidindo com a fase de maturação dos frutos do café. Durante este período, o clima frio não deve reduzir o potencial da mosca-do-mediterrâneo, pois ROSSILLO \& PORTILLO (1971), verificaram na Argentina, que nos meses mais frios do ano, a fecundação e oviposição, e consequentemente, os danos de C.capitata não foram afetados.

São contraditórias as informações à respeito da importância de C.capitata como praga do café. HAMILTON (1967) na Guatemala, SQUIRE (1972) na Bolívia e ABASA (1973) no Quênia, mostraram que $o$ inseto tem pequena importância econômica para a cultura. Por outro lado, RHODE et al. (1971) indicaram C.capitata como praga séria do cafeeiro na Nicarágua. Existem relatos mostrando C.capitata como responsável pela queda prematura de cerejas do cafeeiro (LE PELLEY, 1968; GIBSON, 19 ) e por causar alterações na qualidade da bebida (GIBSON, 1970), enquanto outros estudos evidenciam que ela não causam tais problemas (ABASA, 1973).

No Brasil quase não existem informações relacionadas com danos da mosca-do-mediterrâneo aos frutos do cafeeiro. Bondar citado por NAKANO (1972), observou a ocorrência de frutos chochos e queda de cerejas quando essa mosca atacou frutos ainda verdes e ocorrência de sementes de cor preta, com perda do aroma característico, quando o ataque ocorreu em cerejas já formadas, prestes à maturação.
Ainda Bondar citado por NASCIMENTO (1980), mostrou que C.capitata $E$ encontrada frequentemente em café no planalto baiano, causando danos de $10 \%$. GALLO et al. (1988) relataram que o referido inseto pode causar apodrecimento e queda de frutos e prejudicar a qualidade da bebida.

A determinação da qualidade da bebida do café pode ser avaliada por vários métodos. Inúmeros autores têm demonstrado que a atividade da enzima polifenol oxidase (PFO) em grãos de café verde, está relacionada com a qualidade da bebida do café (a ativi-dade da PFO decresce do melhor para o pior café).

Deste modo, AMORIM \& SILVA (1968), no Brasil, mostraram que esta atividade enzimática pode ser usada como um indicador bioquímico para se distinguir os quatro diferentes tipos comerciais do café brasileiro (classificados de acordo com a qualidade da bebida). Isto foi confirmado por Rotemberg \& Iachan, também no Brasil, Sanint \& Valencia e Valencia na Colombia, e Gopal na Índia, citados por AMORIM (1978) e MELO et al. (1980) no Brasil.

0 método baseado na determinação da lixiviação de potássio das sementes de café também pode ser usado para distinguir cafés de qualidades diferentes. AMORIM (1978) encontrou diferenças significativas na lixiviação de potássio em grãos de café verde que diferiram em qualidade, sendo tanto maior a lixiviação de potássio quanto pior a qualidade do café, indicando que diferentes tipos de danos causados à sementes de café, assim como a variação de umidade e/ou temperatura, afetam a permeabilidade e estrutura das membranas das células, aumentando a lixiviação de potássio e modificando a sua qualidade.

\section{MATERIAL E MÉTODOS}

\section{Experimento de campo}

As plantas utilizadas foram de Coffea arabica L., variedade Catuaí Vermelho, com cerca de 4 anos de idade e localizadas no Departamento de Entomologia da Escola Superior de Agricultura "Luiz de Queiroz" - ESALQ/USP, Piracicaba,SP.

$O$ delineamento estatistico utilizado foi o de blocos casualizados com seis repetições e quatro tratamentos (testemunha, uma fêmea, três fêmeas e cinco fêmeas, liberadas com machos na proporção de 1 fêmea: 2 machos). As parcelas eram constituídas de ramos localizados na parte 
intermediária de plantas diferentes e voltados para a direção Leste, possuindo cada um cerca de $\mathbf{7 5}$ frutos, a maioria dos quais estava verde na época de início do experimento. Os ramos foram individualizados e protegidos por mangas de "voil" branco, que apresentavam uma abertura com velcro, para facilitar a introdução dos adultos de C.capitata. As extremidades das mangas foram amarradas aos ramos com barbante, impedindo a entrada ou saída de insetos. As folhas das pontas dos ramos foram mantidos fora das mangas para que ficassem expostas à luz solar.

Os adultos de C.capitata utilizados tinham 5-6 dias de vida e eram provenientes da criação existente na Seção de Entomologia do Centro de Energia Nuclear na Agricultura (CENA). A liberação dos mesmos foi iniciada em 14.03.91, e a colheita dos frutos efetuada em 27.05.91, ocorrendo neste período, um total de cinco liberações de adultos, pois a cada quinze dias eram efetuadas as avaliações do número de cerejas existentes nos ramos e de possíveis danos existentes nos frutos, seguidas de nova liberação dos insetos. Diariamente, era oferecido alimento (à base de mel, açúcar, glicose e proteína hidrolizada) e água destilada embebida em um pequeno chumaço de algodão, ambos fixados na parte superior da manga.

Os frutos que caíam dos ramos eram retirados das mangas de "voil" e colocados no solo ao lado da planta, onde ficavam isolados por uma tela plástica de $15 \mathrm{~cm}$ de altura. Até 14.04, a contagem destes frutos era feita quinzenalmente; à partir daquela data, a contagem passou a ser diária.

Para a análise da variância e emprego do teste Tukey, os dados sobre número de frutos que caíram foram transformados em $\log (x+1)$.

Após a colheita, foram separadas as cerejas dos demais frutos existentes nos ramos. Nos tratamentos que receberam liberação das moscas, foram consideradas apenas as cerejas que apresentavam puncturas de oviposição e/ou outros danos causados pelas larvas.

A seguir, as cerejas foram colocadas em bandejas de latão submetidas à secagem "via seca", em terreiro atijolado durante seis dias (durante a noite, eram recolhidas para dentro do armazém), sendo depois beneficiadas manualmente.

\section{Determinaçāo da atividade da polifenol oxidase}

As amostras de café foram trituradas num moinho rotatório Tecnal, com tela contendo 20 malhas $/ \mathrm{cm}^{3}$, sendo que imediatamente após, $0,25 \mathrm{~g}$ do pó foi extraído a $5^{\circ} \mathrm{C}$ com $5 \mathrm{ml}$ de tampão fosfato $0,05 \mathrm{M}, \mathrm{pH} 7,0 \mathrm{em}$ almofariz com ajuda de areia lavada. $O$ homogeneizado obtido foi centrifugado $\left(0-5^{\circ} \mathrm{C}\right)$ por 10 minutos a $10.000 \mathrm{rpm}$, sendo o sobrenadante novamente centrifugado nas mesmas condições anteriores. Depois disso, $0,2 \mathrm{ml}$ do extrato foi adicionado a $2,8 \mathrm{ml}$ de solução tampão fosfato $0,05 \mathrm{M} \mathrm{pH} \mathrm{7,0} \mathrm{contendo} 0,125 \%$ de L-DOPA. No controle foi omitido o L-DOPA na solução tampão. Foi usado um espectrofotômetro Perkin-Elmer, ajustado ao comprimento de onda de $420 \mathrm{~nm}$, para se obter as leituras das densidades opticas (DO), as quais foram feitas imediatamente após ter sido adicionado o extrato e 10 minutos ap6s, ambas sob temperatura de $37^{\circ} \mathrm{C}$.

Os resultados definitivos das DO foram obtidos, calculando-se a diferença entre a amostra e o controle. Para cada tratamento, foram usadas três repetições, sendo cada uma analisada em duplicata (adaptado de AMORIM, 1978).

\section{Determinação da lixiviação de potássio}

As sementes foram pesadas e colocadas individualmente em pequenos copos plásticos com $10 \mathrm{ml}$ de água distilada $\mathrm{e}$ mantidas por 24 horas $\mathrm{em}$ uma estufa a $25^{\circ} \mathrm{C}$ e $100 \%$ UR.

A seguir, a lixiviação de potássio foi obtida através das análises das amostras num fotômetro de chama Digimed NK-2002. Foram usadas quatro sementes para cada repetição do experimento, perfazendo um total de 24 sementes analisadas por tratamento (adaptado de AMORIM, 1978).

\section{RESULTADOS E DISCUSSÃO}

Do total de 222 frutos que sofreram queda dos ramos, apenas 3,6\% eram verdes, correspondentes à queda de dois frutos por tratamento.

Além disso, apenas em cerejas se observou puncturas de oviposição de C.capitata, o mesmo não sendo notado nos frutos verdes, evidenciando que estes frutos não foram atacados pela mosca-domediterrâneo.

Tais resultados diferem daqueles encontrados por Bondar citado por NAKANO (1972), que observou danos da mosca-domediterrâneo em frutos verdes de café.

As cerejas apresentaram $46,4 \%$ dos frutos que caíram dos ramos, sendo na sua totalidade cerejas completamente maduras (apenas quatro apresentavam-se parcialmente amareladas). 
TABELA 1 - Número médio de frutos que caíram dos ramos que estiveràm presentes nos ramos dos cafeeiros sob à ação de diferentes níveis populacionais de C.capitata, durante o período de 14.03 a 27.05.91.

\begin{tabular}{cccccc}
\hline & \multicolumn{2}{c}{ Total médio de frutos que caíram dos } & & \multirow{2}{*}{$\begin{array}{c}N^{0} \text { médio de } \\
\text { cereja }\end{array}$} & Total de \\
\cline { 2 - 3 } Tratamos & secos & & nos ramos & cerejas \\
\hline Testemunha & cerejas & $2,5 \mathrm{a}$ & 6,0 & 35,8 \\
01 fêmea & $1,1 \mathrm{~b}^{2}$ & $3,9 \mathrm{a}$ & 5,5 & 33,1 \\
03 fêmeas & $5,4 \mathrm{ab}$ & $7,0 \mathrm{a}$ & 6,2 & 38,3 \\
05 fêmeas & $7,8 \mathrm{a}$ & $5,0 \mathrm{a}$ & 4,6 & 27,4 \\
\hline \hline
\end{tabular}

1 Total médio de cerejas que ocorreram nos ramos, inclusive que caíram.

${ }^{2}$ Médias seguidas verticalmente pela mesma letra, não diferem entre si pelo teste de Tukey, a $5 \%$ de probabilidade

Deste modo, C.capitata não chegou a causar queda prematura de frutos, mas seu ataque aumentou significativamente a queda de cerejas (TABELA 1).

Este fato pode ocasionar um dano indireto, pois os frutos que caem no solo são responsáveis por uma bebida de pior qualidade, quando ali permanecem por um período de mais ou menos 15 dias (AMORIM \& AMORIM, 1977; AMORIM, 1978), o que pode ser confirmado pelos resultados existentes na TABELA 2.

Os frutos secos representaram $50 \%$ dos que sofreram queda dos ramos, não sendo observada diferença significativa entre os tratamentos (TABELA 1).

$O$ fato inesperado de haver ocorrido maior queda de cerejas nos ramos onde foram liberadas três fêmeas da mosca-do-mediterrâneo, do que no tratamento com 5 fêmeas/ramo, possivelmente pode ser explicado por ter ocorrido neste tratamento, uma alta densidade de fêmeas em relação a baixa disponibilidade de cerejas (isto foi agravado no tratamento com 5 fêmeas/ramo, em que a disponibilidade de cerejas foi menor que nos demais (TABELA 1). Nestas condições, no tratamento com fêmeas, deve ter sido grande a ocorrência de fêmeas ovopositando nas mesma cereja, o que foi altamente desfavorável a sobrevivência das larvas (PROKOPY \& ROITBERG, 1989) e em consequência disto, os danos foram menores que nos outros tratamentos.
A análise da atividade do polifenol oxidase (PFO) mostrou uma forte evidência de qué o ataque de Ceratitis capitata diminuiu a qualidade $\mathrm{da}$ bebida, pois a referida atividade foi menor nas amostras de café provenientes dos tratamentos que receberam moscas (TABELA 2).

Além disso, sementes provenientes daqueles tratamentos, tambem apresentaram níveis mais altos de lixiviação de potássio, aumentando as evidências de que elas apresentavam características de café de pior qualidade.

No entanto, deve ser ressaltado que tais resultados devem ser confirmados por novos estudos, incluindo a determinação da qualidade da bebida por degustadores profissionais, uma vez que na metodologia empregada no presente trabalho, as conclusões foram baseadas em dois procedimentos físico e químico, que tornam não definitivamente conclusivos, os resultados obtidos.

Um outro aspecto, refere-se à secagem "via seca" das cerejas, a qual pode ter favorecido a ocorrência de uma fermentação mais intensa de natureza variada nas cerejas atacadas por C.capitata comparadas com o controle, devido os danos existentes terem facilitado a penetração de microrganismos, contribuindo para que aquelas cerejas produzissem um café de pior qualidade (AMORIM \& AMORIM, 1977). Para esclarecer este fato, seria necessário, em cada tratamento, secar parte das cerejas pelo processo "via seca" (como faz o agricultor tradicional) e parte sofrer 
despolpa para que a secagem das sementes ocorresse na forma de pergaminho (da maneira que procedem agricultores mais tecnificados).

TABELA 2 - Atividade da polifenol oxidase (DO 420/10 minutos) ${ }^{1}$, em grãos de café verde, originados de cerejas submetidas a diferentes níveis populacionais de C.capitata (cada valor representa a média de 3 repetições analisadas em duplicata).

\begin{tabular}{cc}
\hline Tratamentos & D0420 (Ramo) \\
\hline Testemunha & 0,141 \\
01 fêmea & 0,122 \\
03 fềmeas & 0,111 \\
05 fềmeas & 0,119 \\
\hline \hline
\end{tabular}

1 Variação de densidade óptica.

TABELA 3 - Lixiviação de potássio de grãos de café verde, originados de cerejas submetidos a diferentes níveis populacionais de C.capitata (cada valor representa a média de 6 repetições).

\begin{tabular}{cc}
\hline Tratamentos & ppm Kp ${ }^{+} / \mathrm{g}$ grāo verde \\
\hline Testemunha & 72,8 \\
01 fềmea & 87,8 \\
03 fềmeas & 100,9 \\
05 fêmeas & 88,9 \\
\hline
\end{tabular}

Assim, poderia ser individualizado o efeito do ataque da mosca-do-mediterrâneo nos parâmetros físicos e químicos medidos, e na qualidade da bebida, bem como definido se o ataque das cerejas pela mosca afeta a qualidade dos grãos ainda na planta, ou se contribui para a ocorrência de uma bebida de pior qualidade, devido às consequências deste ataque durante a secagem "via seca". Se esta segunda hipótese for correta, o procedimento de despolpa da cereja para secagem seria uma vez mais justificado e seria imprescindivel para cafezais que sofressem ataque severo da mosca-do-mediterrâneo e/ou outras espécies de moscas-das-frutas.

A imperfeição experimental discutida, não pode ser evitada no presente trabalho, porque o número de cerejas danificadas pela mosca-domediterrâneo não foi suficiente para tal. Deste modo, para que em experimentos futuros seja possível a análise da qualidade da bebida (teste da xícara, PFO e lixiviação de potássio), a quantidade de cerejas a ser obtida por parcela, apresentando sintomas semelhantes do ataque de $C$. capilata, deve ser suficiente para que sejam obtidas, pelo menos, $160 \mathrm{~g}$ de sementes verdes em cada processo de secagem recomendado.

\section{AGRADECIMENTOS}

Ao Prof. Dr. JOSÉ DIAS COSTA, Dr. WALTER ARTHUR e ao Engo Agro CÁSSIO EGÍDIO CAVENEGHI PRETE, que colaboraram na instalação e execução do experimento.

\section{REFERÊNCIAS BIBLIOGRÁFICAS}

ABASA, R.O. Observations on the seasonal emergence of fruit on a Kenya coffee estate and studies of the pest status of Ceratitis capitata Wied. in coffee. East African Agricultural and Forestry Journal, Nairobi, v.39, n.2, p.144-148, 1973.

AMORIM, H.V. Aspectos bioquímicos e histoquímicos do grão de café verde relacionaods com a deterioração da qualidade. Piracicaba, 1978. 85p Tese (LivreDocência) - Escola Superior de Agricultura "Luiz de Queiroz", Unjversidade de São Paulo.

AMORIM, H.V.; AMORIM, V.L. Coffee enzyme and coffee quality. In: ORY, R.L. \& ANGELO, A.J. St., (Ed.). Enzymes in food and beverage processing. Washington: American Chemical Society, 1977. p.27-56. (ACS. Symposium Series, 47).

AMORIM, H.V.; SILVA, D.M. Relationship between the polyphenol oxidase activity of coffee beans and the quality of the beverage. Nature, London, v.219, p.381-382, 1968.

CUCULIZA, T.M.; TORRES, V.E. Moscas de la fruta en las principales hospederas del Vale de Huanuco. Revista Peruana de Entomologia, Lima, v.18, n.1, p. $76-79,1975$.

DAXL, R. Mediterranean fruit fly ecology in Nicaragua and a proposal for integrated control. Plant Protection Bulletin, Roma, v.26, n.4., p.150-157, 1978.

GALLO, D.; NAKANO, O.; SILVEIRA NETO, S.; CARVALHO, R.P.L.; BATISTA, G.C.; BERTI FILHO, E.; PARRA, J.R.P.; ZUCCHI, R.A.; ALVES, S.B.; VENDRAMIN, J.D. Manual da entomologia agricola, 2.ed., São Paulo, Ceres, 1988. 649 . 
GIBSON, A. Fruit fly damage in Kenya coffee and its possible effect on quality. Kenya Coffee, Nairobi, v.35, p.260-266, 1970.

HAMILTON, D.W. Injuries and beneficial insects in coffee plantations of Costa Rica and Guatemala. Journal of Economic Entomology, Lanham, v.60, p.1409-1413, 1967.

INSTITUTO BRASILEIRO DO CAFE. Importância econômica. In: Cultura do café no Brasil: pequeno manual de recomendaçōes. Rio de Janeiro. 1986, p.17.

LE PELLEY, R.H. Peste of coffee. London: Longmans, 1968. 590p.

MALAVASI, A. Aspectos da biologia populacional e genética de Anastrepha (Diptera: Tephritidae). São Paulo, 1977. 144p. Tese (Doutorado) - Instituto de Biologia, Universidade de Sāo Paulo.

MALAVASI, A.; MORGANTE, J.S.; ZUCCHI, R.A. Biologia de "moscas-de-frutas" (Diptera: Tephritidae). I: Lista de hospedeiros e ocorrência. Revista Brasileira de Biologia, Rio de Janeiro, v.40, n.1, p.9$16,1980$.

MARICONI, F.A.M.; IBA, S. A mosca-domediterrâneo. O Biologico, São Paulo, v.2, p.17-32, 1955.

MATIOLI, J.C. Moscas das frutas, situação e perspectivas de controle no Brasil. Defesa Vegetal \& Animal, São Paulo, v.27, p.19-26, 1985.

MELO, M.; FAZUOLLI, L.C.; TEDXERA, A.A.; AMORIM, H.V. Alterações físicas, químicas e organolépticas em grăos de café armazenados. Ciência e Cultura, São Paulo, v.32, n.4, p.468-471, 1980.

NAKANO, O. Pragas do cafeeiro. In: CURSO INTENSIVO DE CAFEICULTURA, Piracicaba, 1972. Piracicaba: ESALQ, 1972. p.82-103.

NASCRENTO, A.S. do. Dinâmica populacional de moscas de frutas (Diptera: Tephritidae) no recôncavo baiano. Piracicaba, 1980. 110p. Dissertação (Mestrado) - Escola Superior de Agricultura "Luiz de Queiroz", Universidade de São Paulo.
NUNEZ-BUENO, L. La mosca del mediterrâneo. ICA Informa, Bogotá, v.21, n.1, p.9-17, 1987.

PARRA, J.R.P.; ZUCCHI, R.A.; SILVEIRA NETO, S. Flutuação populacional e atividade diária de vốo da mosca-do-mediterrâneo em cafeeiros "Mundo Novo". Pesquisa Agropecuária Brasileira, Brasilia, v.17, n.7, p.985-92, 1982.

PROKOPY, R.J.; ROTTBERG, B.D. Fruit fly foraging behavior. In: ROBINSON, A.S. \& HOOPER, G. (Ed.). Fruits files, their biology, natural enemies and control. Amsterdan: Elsevier, 1989.v.3A, p.293306.

PUZZI, D.; ORLANDO, A.; RIBAS, C. O emprego dos frascos "caça-moscas" no combate às moscas das frutas. O Biologico, São Paulo, v.23, p.189-196, 1957.

RODHE, R.H.; SMMN, J.; PERDOMO, A.; GUTIERREZ, J.; DOWLING Jr, C.F.; LINDQUIST, D.A. Application of the sterile-insect-release technique in mediterranean fruit fly suppresion. Journal of Economic Entomology, Lanham, v.64, p.708-713, 1971.

ROSSILlo, M.A.; PORTILlo, M.M. Fatores que detien el incremento de la densidade de poblacion de las especies Anastrepha fraterculus y Ceratitis capitata. Revista Peruana de Entomologia, Lima, v.14, n.2, p.323-333, 1971.

SOUZA, H,M.L.; PAVAN, O.H.; NECCHIO, M.C.D.; CONTI, E.A.; ARRUDA, V.L.V. Moscas de frutas em cafe Novo Mundo (Coffea arabica) e em Citrus calamundin. In: REUNIÃO ANUAL DA SOCIEDADE BRASILEIRA PARA O PROGRESSO DA CIÊNCIA, 17., 1975, Belo Horizonte, Resumos. Ciencia e Cultura. Suplemento, São Paulo, v.27, n.7, p.368, jul., 1975.

SQUIRE, F.A. Entomological problems in Bolivia. PANS, London, v.18, n.3, p.249-268, 1972.

Trabalho enviado para publicação em 16.08.92 Trabalho aceito para publicação em 18.11 .92 